\title{
LA GENÉTICA Y LA BIOTECNOLOGÍA EN LAS FRONTERAS DEL DERECHO
}

\author{
Carlos María Romeo Casabona*
}

\begin{abstract}
Resumen: El Derecho relativo al genoma humano y a las biotecnologías ha ido transitando paulatinamente -sobre todo en el ámbito del Derecho Internacional- desde un soft law (normas jurídicas no esencialmente obligatorias ni coercitivas, sino más bien exhortativas), hacia un Derecho caracterizado por normas de carácter obligatorio, respaldadas, cada vez con mayor frecuencia, por sanciones y otras consecuencias jurídicas.

En este sentido, asistimos a la remodelación de valores vinculados con el genoma humano, cuya protección jurídica podría configurarlos como derechos subjetivos o bienes jurídicos. Entre ellos, podemos destacar: la necesidad de respetar al ser humano, tanto en cuanto persona como por su pertenencia a la especie humana; la responsabilidad de las actuales generaciones para con las futuras; la protección de la identidad del ser humano (personal y biológica o genética); la consideración del genoma humano como patrimonio de la humanidad; el reconocimiento de la diversidad biológica, etc.
\end{abstract}

Palabras clave: Genética, biotecnología, bioética, genoma humano, derechos humanos

\section{GENETICS AND BIOTECHNOLOGY AT THE BORDER OF LAW}

\begin{abstract}
Law concerning the human genome and biotechnologies has moved slowly -especially in the scope of International Law- from a soft law (juridical norms not essentially compulsory or coercive, but rather exhortative), towards a Law characterized by obligatory rules, backed, more and more frequently, by penalties and other juridical consequences.

In this sense, we attend to the remodeling of values linked to the human genome, whose juridical protection might characterize them as subjective rights or juridical benefits. Among them we may point out: the need to respect the human being, both as a person and as belonging to the human species; the responsibility of today's generations in regard to the future ones; the protection of the human identity (personal and biological or genetic); the consideration of the human genome as humanity's patrimony; the acknowledgement of biological diversity, etc.
\end{abstract}

Key words: Genetics, biotechnology, bioethics, human genome, human rights

\section{GENÉTICA E BIOTECNOLOGIA NAS FRONTEIRAS DO DIREITO}

Resumo: O Direito relativo ao Genoma humano e as biotecnologias têm transitado progressivamente - sobretudo no Direito Internacional - desde a condição de "soft law” ( normas jurídicas não essencialmente obrigatórias nem coercitivas mas aconselhadoras), até o Direito caracterizado por normas de caráter obrigatório, respaldadas cada vez com maior freqüência, em sanções penais e outras conseqüências jurídicas.

Nesse sentido, assistimos a remodelação de valores vinculados ao genoma humano, cuja proteção jurídica poderia configurá-las como direitos subjetivos ou bens jurídicos. Nesse particular, podemos destacar: a necessidade de respeito ao ser humano, tanto como pessoa como por pertencer a espécie humana; a responsabilidade das atuais com futuras gerações; a proteção de identidade do ser humano ( pessoal, biológica ou genética); a caracterização do genoma humano como patrimônio da humanidade; o reconhecimento da diversidade biológica, etc...

Palavras chave: Genética, biotecnologia, bioética, genoma humano, direitos humanos

\footnotetext{
* Profesor de Derecho Penal. Director de la Cátedra Interuniversitaria Fundación BBVA - Diputación Foral de Bizkaia de Derecho y Genoma Humano, Universidad de Deusto y Universidad del País Vasco/EHU.

Correspondencia: cromeo@genomelaw.deusto.es
} 


\section{En las fronteras del Derecho}

Una de las funciones del Derecho consiste en identificar los valores implicados en cada caso concreto, en cada situación conflictiva. Pero a este respecto debe tenerse presente la famosa frase de que el siglo XX se ha caracterizado por el gran desarrollo y eficacia de los medios, pero al mismo tiempo por una confusión en los fines. ¿Ocurrirá algo semejante en el siglo XXI? ¿De dónde se deberá nutrir el Derecho para identificar esos valores? ¿Qué cometido corresponderá en este sentido a la Bioética?

En primer lugar, debe señalarse un principio metódico imprescindible: la necesidad de que la sociedad revise sus propias valoraciones, sus principios axiológicos, en relación con los nuevos conflictos de las ciencias biomédicas. Los motivos de esta perspectiva metodológica se basan en que puede venir exigida por esas novedades que aportan en general la Ciencia y la Tecnología; en que no siempre las valoraciones tradicionales dan respuestas adecuadas a las nuevas situaciones: no existe una identidad o coincidencia entre el supuesto de hecho (nuevo) y los valores que se pretenden aplicar o que parecen aplicables; se trata de una subsunción errónea entre hecho y valor ${ }^{1}$. Por consiguiente, en estos casos, puede ser necesario construir valores nuevos que se adapten, que den respuesta al nuevo supuesto de hecho.

No obstante, no deben descartarse algunos riesgos o peligros que podrían derivarse de esta metodología, por lo que deben ser detectados con el fin de poder prevenirlos. En primer lugar, puede abrir las puertas a un relativismo excesivo de los valores. Por otro lado, este principio metódico puede favorecer una especie de

\footnotetext{
Algo semejante ocurrió cuando Christian Barnard realizó con éxito el primer trasplante de corazón en 1966, para lo que tuvo que apoyarse en un concepto de muerte desconocido para la sociedad, aunque no para la Medicina: la muerte cerebral.
}

seguidismo del curso de las investigaciones y de sus resultados, o al menos puede propiciar que se le dirija una acusación de semejante índole; es decir, que esta búsqueda de valores nuevos para situaciones nuevas se haga en función de las necesidades que puedan tener los investigadores y científicos en un momento dado, lo que comporta un riesgo de pérdida de la iniciativa respecto a la reflexión ética y jurídica. Y, finalmente, y es más grave, podría acusarse a quienes sigan tal proceder de pretender aportar una legitimación a las necesidades de la ciencia, esto es, de buscar a toda costa la justificación ética a los conflictos que van planteando los avances científicos y las necesidades o exigencias de los investigadores (y, dado el caso, de las empresas del sector). Debe reconocerse que en tales circunstancias la Bioética y el Derecho pasarían de ser un discurso sobre el comportamiento correcto o socialmente tolerable, respectivamente, a un mero instrumento legitimador de la ciencia. Y es sabido que la ciencia no es neutra desde un punto de vista axiológico.

\section{El genoma humano, un nuevo paradigma para la reflexión sobre la ciencia}

El siglo veinte ha estado cuajado de importantísimos descubrimientos científicos e innovaciones tecnológicas que han afectado de forma muy notable a las relaciones interindividuales, a las estructuras sociales y al desarrollo económico, por lo general con efectos beneficiosos. En el umbral del nuevo siglo destacan las aportaciones de la Biología y la Medicina y de las Nuevas Tecnologías de la Información y la Comunicación.

En efecto, el desarrollo de la Biología Molecular a lo largo de las últimas décadas ha sido enorme y prometedor. Todo ello está siendo posible gracias a varias acciones de investigación sobre el genoma humano. Algunas de ellas fueron coordinadas internacionalmente y se conocen como el "Proyecto Genoma Humano". 
1. Las investigaciones sobre el genoma humano se están viendo favorecidas como consecuencia de la culminación del objetivo principal que perseguía el Proyecto Genoma Humano: la secuenciación completa del ADN humano y la cartografía linear de los genes en los cromosomas. En la actualidad, la comunidad científica tiene entre sus objetivos mediatos o inmediatos profundizar en el conocimiento de las características del ADN humano y de sus componentes integrantes, en particular de los genes, y en relación con éstos el de sus funciones y su concreta participación respectiva en la transmisión de la herencia biológica. Como consecuencia de ello podrá avanzarse también en la identificación de los genes responsables de la aparición de determinadas enfermedades (genes deletéreos), así como de los mecanismos de su manifestación, de su transmisión y de su posible tratamiento o prevención $\mathrm{y}$, en fases mucho más avanzadas y tardías de la investigación, tal vez incluso cuáles podrían influir en la aparición de ciertas tendencias, habilidades o capacidades de las personas.

Una de las características más peculiares de la información genética es su capacidad predictiva, pues su anticipación puede abarcar incluso enfermedades respecto a las cuales el individuo es todavía asintomático, es decir, cuando ni siquiera está padeciendo la enfermedad o todavía no ha manifestado sus primeros síntomas en el momento en el que se somete a las pruebas analíticas pertinentes. Esta capacidad predictiva es especialmente significativa en relación con las enfermedades monogénicas, de las que es responsable un solo gen deletéreo, bien dominante (basta con que uno de los dos heredados de ambos progenitores sea defectuoso para que la enfermedad aparezca), bien recesivo (sería necesario que ambos progenitores transmitiesen el gen deletéreo para que se manifestase la enfermedad; si sólo lo transmite uno de los padres, el hijo será sano, pero portador de la enfermedad, que podrá a su vez transmitir a sus propios hijos). Pero lo es menos en relación con las enfermedades plurigénicas en las que, además de intervenir varios genes, incluso situados en cromosomas diferentes, es necesaria la concurrencia de otros factores exógenos o ambientales (por ello se conocen como enfermedades plurifactoriales), en ambos casos por mecanismos no bien conocidos en la actualidad y por ello se habla en sentido más propio de susceptibilidad o predisposición para padecer la enfermedad.

Los análisis y los diagnósticos genéticos están teniendo una importancia capital también en relación con la reproducción humana, natural o asistida (diagnósticos preconceptivo -realizado sobre la pareja-, preimplantatorio sobre el embrión in vitro- y prenatal -sobre el feto-). Dada la complejidad que revisten estos procesos y las dificultades que supone frecuentemente la adopción de las decisiones más convenientes para los interesados, se ha impuesto el llamado consejo genético.

Una vez trasladados estos recursos a individuos concretos, la realización de análisis genéticos a personas determinadas puede revelar información muy importante de carácter personal y familiar, como son datos biológicos sobre ciertos rasgos fenotípicos del afectado, incluidos los étnicos; sobre su salud física y mental presente y futura; asimismo, sobre su capacidad reproductiva y la salud de la descendencia presente y futura; puede evidenciar también relaciones con terceras personas (así, de paternidad, participación en la comisión de un delito) o facilitar su identificación en ciertas circunstancias (cadáveres en casos de accidentes o de catástrofes), aunque en ambos casos a través de la información que proporciona principalmente el ADN no codificante. En resumen, la mayor parte de la información genética se proyecta sobre la salud de los individuos, pero como se ha visto, no toda ella debe identificarse con la salud. 
Los análisis genéticos están posibilitando cada vez con mayor precisión y amplitud la diagnosis de patologías vinculadas con la herencia, incluso antes de que se produzcan las primeras manifestaciones o síntomas de la enfermedad correspondiente.

2. Por su parte, las biotecnologías constituyen un poderoso instrumento para contribuir eficazmente a la lucha contra las enfermedades hereditarias, así como contra otras de origen microbiano (virus, bacterias, hongos, parásitos, etc.) o debidas a desequilibrios del funcionamiento bioquímico del organismo.

Diversos medicamentos que incluyen ya proteínas como principio activo, así como vacunas y productos diagnósticos destinados al consumo humano, han sido obtenidos en grandes cantidades, primero a partir de organismos naturales, pero también por ingeniería genética, recurriendo a genes humanos aislados. Con la farmacogenética y la farmacogenómica se pondrán a disposición nuevos medicamentos adaptados a las propias características del paciente o, lo que es lo mismo, medicamentos individualizados y más efectivos que en la actualidad, al tiempo que disminuirán sus frecuentes efectos secundarios (yatrogenia).

Por otro lado, desde tiempos remotos el ser humano ha intentado modificar de algún modo las especies vivas, tanto vegetales como animales, con el fin de utilizar sus efectos en su propio provecho, sobre todo en la agricultura y la ganadería. En épocas más recientes estos esfuerzos se han centrado también en la industria misma y, en particular, en la investigación preclínica.

Como puede deducirse de esta muestra de ejemplos, la Biotecnología implica la aplicación de conocimientos de numerosos sectores científicos e ingenierías con el fin de desarrollar procesos productivos; dicho en otros términos, consiste en la aplicación de diversas técnicas sobre la materia viva. La Biotecnología moderna, actual, se vale fundamentalmente de la ingeniería genética.

\section{Perfil de los principales conflictos éticos y jurídicos}

\subsection{La gran carrera: la culminación de la secuenciación del genoma humano}

Ya se ha señalado cómo la obtención de la secuenciación completa del genoma humano es un acontecimiento importante, relativamente. Pero los dilemas que planteó este nuevo paso eran otros: ¿cumpliría finalmente la empresa que había conseguido la secuenciación completa su compromiso de dar a conocer libremente estos descubrimientos a la comunidad científica? $\mathrm{Su}$ decisión de exigir una contraprestación económica a otros investigadores por la información suministrada no era objetable: estaba en su derecho de hacerlo. Pero entonces esa información sólo tendría valor económico mientras permaneciera en secreto, aparte de que lo ya secuenciado -la mayor parte- por otros laboratorios públicos y privados norteamericanos y europeos fue de conocimiento público.

La manera de proteger de forma más efectiva esa información sería la concesión de la patente, pues aquélla estaría protegida sin necesidad de permanecer en secreto, y la explotación de la patente podría generar sustanciosos beneficios económicos. Sin embargo, para que algo sea patentable ha de tratarse de un invento, es decir, de un producto o procedimiento antes inexistente, que comporte una novedad y que tenga alguna aplicación práctica conocida. Es discutido -y tal vez también discutible- que esto ocurra en sentido estricto con la secuenciación del genoma humano en sí misma, pues podría tratarse en realidad de un descubrimiento, de mostrar algo que ya existía; y podría ser 
problemático demostrar alguna aplicación conocida, si no se sabe qué funciones concretas desempeñan esas bases nitrogenadas.

Con la genómica y la proteómica se abren nuevos retos científicos y, al mismo tiempo, nuevos aspectos para la reflexión ética y para posibles regulaciones jurídicas.

Desde los inicios del Proyecto Genoma Humano se tuvo conciencia de que el éxito de las investigaciones debía contar con un poderoso e imprescindible instrumento: los sistemas informáticos, que han experimentado un impresionante desarrollo en el sector. La bioinformática ya fue decisiva para la conclusión del mapeado del genoma humano, al acelerar de forma espectacular la secuenciación de las bases nitrogenadas del ADN y en la actualidad prosigue su contribución como instrumento, tanto en el procesamiento y almacenamiento de esas moléculas (bases de datos biogenéticas) como en la comprensión de estas estructuras, sus funciones bioquímicas y su comportamiento biológico.

\subsection{Los datos genéticos}

La faceta ambivalente que venimos apuntando sobre estas investigaciones y sus descubrimientos se manifiesta de forma casi inherente en los análisis genéticos. Como es sabido, son una realidad ya casi cotidiana de la sanidad presente, con la valiosa información que proporcionan y que, gracias a la progresión de las investigaciones, están ampliando sin cesar su espectro de obtención de información y ganando al mismo tiempo en exactitud y en capacidad predictiva. Esta información es de sumo interés, no sólo para el sujeto de quien proviene, es decir, para quien ha sido sometido a los análisis genéticos, sino también para terceros, como son, en primer lugar, sus familiares biológicos; pero también para otras personas o entidades, en cuanto se propugne la garantía de un organismo potencialmente sano como presupuesto para participar en ciertas actividades, incluso para el Estado en su acción política de prevenir enfermedades y promover una población más sana.

De forma inmediata surge la cuestión de si el sometimiento a estas pruebas podría hacerse obligatorio, imponerse incluso coercitivamente o condicionar ciertas relaciones y prestaciones a dicho sometimiento voluntario, pero en último extremo coactivo, $\mathrm{y}$ en términos semejantes puede presentarse la cuestión del acceso mismo a los resultados de esas pruebas por parte de terceros o del propio afectado ${ }^{2}$. Como consecuencia de estas posibilidades, parece necesario replantearse qué nuevas dimensiones se presentan en relación con la protección de los derechos a la intimidad y a la vida privada, así como frente a cualquier forma de discriminación basada en las características genéticas de cada individuo.

\subsection{Las intervenciones en los genes, ¿hacia una nueva eugenesia?}

También presentan unas facetas ambivalentes las intervenciones en el genoma, por su potencialidad modificadora de ciertas características biológicas de los individuos, modificaciones que, a su vez, pueden ser transmitidas por los mecanismos de la herencia biológica. Estas técnicas son muy variadas, pues pueden consistir en la modificación de genomas o de genes aislados, bien en células ya diferenciadas (línea somática), bien en los gametos o en el embrión en sus primeras fases, cuando sus células son todavía indiferenciadas o totipotentes (línea germinal); o en la selección de cromosomas (en especial los cromosomas ' $\mathrm{x}$ '

\footnotetext{
No podemos entrar en la importante casuística que generan estos conflictos, pero recuérdense algunos supuestos más relevantes: en relación con diagnósticos de otros miembros de la misma familia, en el ámbito de los seguros (de vida, de enfermedad, de accidentes), del empleo (acceso a un puesto de trabajo, promoción interna) y de las relaciones crediticias, entre otros que serán analizados más adelante.
} 
e ' $y$ '); en el intercambio o transferencia de ADN nuclear o mitocondrial (clonación, etc.); o en la actuación sobre agentes infecciosos a partir del propio $A D N$ (p. ej., el virus de inmunodeficiencia humana adquirida, VIH). Bien es cierto que no pueden dejarse a un lado los objetivos perseguibles con estas técnicas diversas, pues pueden perseguir tanto fines terapéuticos o preventivos, adelantándose a la manifestación de la enfermedad, como otros perfectivos o de mejora del individuo nacido o por nacer.

En este panorama se abren, por consiguiente, otras puertas que apuntan a un horizonte todavía indefinido: la eugenesia. La tentación eugenésica, cierto que con intermitencias, ha sido una constante en la historia de la humanidad; no sería, por consiguiente, un fenómeno nuevo( 1 3). Este ideal perfeccionista tuvo que pasar previamente por procedimientos expeditivos tendentes a impedir el nacimiento, la supervivencia o la reproducción de seres "imperfectos": eutanasia neonatal, aborto o esterilización de individuos considerados atávicos o mentalmente anormales.

En la actualidad, los análisis genéticos preconceptivo, preimplantatorio y prenatal son un instrumental precioso que aporta la ciencia, pero que pueden ser utilizados en favor de estas corrientes, que han resurgido en la actualidad como la "nueva eugenesia" o "neoeugenesia", pues presenta aspectos nuevos y enfoques diferentes a cualquier concepción anterior.

Las reflexiones sobre los posibles efectos de la eugenesia actual (de eugenesia positiva, fundamentalmente) y la protección de la especie humana, han dado lugar a que se haya planteado la necesidad de garantizar una protección especial y específica del genoma humano.

\subsection{Bioseguridad y biodiversidad}

De forma paralela debe abordarse el análisis jurídico de la protección del medio ambiente (bioseguridad), que también puede verse afectado por las manipulaciones genéticas sobre los seres vivos no humanos ${ }^{3}$, bien es cierto que en ocasiones se ha recurrido precisamente a la Biotecnología como medio de protección (por ejemplo para las catástrofes producidas en la vida marina provocadas por derrames masivos de petróleo). La preservación de la biodiversidad ha sido asimismo objeto de atención semejante, no sólo por la riqueza que entraña en cuanto tal, sino también porque constituye al mismo tiempo una garantía para la pervivencia de las especies, incluida la humana.

Como veremos más adelante, la preocupación de instancias internacionales y supranacionales ha dado lugar a normativas dirigidas a controlar la utilización confinada de microorganismos manipulados genéticamente y a la protección de la biodiversidad ${ }^{4}$.

\subsection{La libertad de investigación}

Para completar esta global, breve e introductoria incursión en algunas situaciones conflictivas y aplicaciones abusivas o perversas del conocimiento científico sobre el genoma humano, no debe dejarse en el olvido que los constantes descubrimientos sobre aquél y las numerosas aplicaciones a que han dado lugar en

\footnotetext{
Alude a ello en su Exposición de Motivos la Ley española $15 / 1994$, de 3 de junio, por la que se establece el régimen jurídico de la utilización confinada, liberación voluntaria y comercialización de organismos modificados genéticamente, con el fin de prevenir los riesgos para la salud humana y para el medio ambiente: "La aplicación de estas técnicas [de manipulación genética] supone grandes posibilidades de desarrollo económico y mejora de la calidad de vida de la humanidad, pero conlleva la responsabilidad de asegurar que dicha aplicación se realice en condiciones en las que los posibles riesgos para la salud humana o el medio ambiente sean mínimos, lo que exige la adopción de una serie de medidas de garantía y control de las actividades en las que se produzcan o empleen organismos modificados genéticamente".

4 Véase la Conferencia sobre el medio ambiente y el desarrollo, Naciones Unidas: Convenio sobre Diversidad Biológica, aprobado en Río de Janeiro el 5 de junio de 1992, y su Protocolo de Cartagena de Indias de 2000; también las Directivas de la Comunidad Económica Europea 90/219/CEE, sobre la utilización confinada de microorganismos modificados genéticamente, y 90/220/CEE.
} 
beneficio del ser humano, de la sociedad y del progreso de la ciencia, han sido posibles gracias al importantísimo apoyo que se ha venido prestando a estas investigaciones, pero es cierto que han encontrado otro ineludible y no menos importante soporte en la libertad de investigación, en el derecho fundamental a la creación y la producción científicas. Pero puesto que todo derecho, aunque sea fundamental, está sometido a ciertos límites, ¿cuáles serán los de la investigación? He aquí el origen de una tensión dialéctica, que en ocasiones puede conducir a la incomprensión recíproca entre investigadores y otros agentes sociales.

Tampoco debería dejar de prestarse atención a la necesidad de configurar un adecuado marco jurídico de protección a las innovaciones en el campo de la Biotecnología y de la Genética humana en particular.

La dimensión social de la investigación comporta, finalmente, unas exigencias, como es el libre acceso por parte de los miembros de la comunidad al conocimiento científico (del que serían beneficiarios, en primer término, los propios investigadores) y a los logros de aquélla, sin discriminaciones por motivos geográficos, culturales, económicos u otros, si bien tal deseo sea más fácil de expresar que de ponerlo en la práctica.

\section{El papel dinámico de los derechos humanos en relación con el genoma humano}

Es casi ya un lugar común resaltar la vinculación cada vez más frecuente y estrecha entre los avances y aplicaciones de las Ciencias Biomédicas y los derechos de los individuos, de forma que, en ocasiones, tal vinculación se presenta como una intensa tensión dialéctica, en particular cuando colisionan entre sí valores individuales o éstos con otros supraindividuales o colectivos. Los juristas, pero no sólo ellos, se han esforzado, también en este ámbito, en el desarrollo de los derechos humanos o en la identificación de nuevos derechos o de nuevos titulares de los mismos, estableciendo al mismo tiempo las relaciones y jerarquías entre ellos. Tarea de inacabada reconstrucción de la teoría de los derechos humanos que, por cierto, no es nueva y que, en sus sucesivas secuencias en el tiempo, ha dado lugar a la identificación de grupos o "generaciones de derechos humanos"(4). En relación con las Ciencias Biomédicas se verían afectadas varias de estas generaciones de derechos humanos e, incluso, estarían dando lugar al nacimiento de una nueva generación, esta vez vinculada con las aportaciones más recientes de las ciencias y las tecnologías, en particular de la genética, las biotecnologías y las nuevas tecnologías de la información y la comunicación.

Esta tarea ha de partir, necesariamente, de varios presupuestos: el primero, de la realidad que pretende ser objeto de análisis jurídico, esto es, de los datos biológicos, los descubrimientos y sus posibles aplicaciones, tanto actuales como razonablemente realizables en un futuro más o menos próximo. El segundo presupuesto consiste en tener en cuenta las valoraciones aportadas en el debate ético que ha generado la cuestión, si no queremos correr el riesgo de que el Derecho sea ciego(5). Finalmente, han de tenerse en cuenta las construcciones, sobre todo en Derecho Internacional, pero que van emergiendo también en Derecho Constitucional(6), desde el prisma de los derechos humanos y de otros principios o valores que pueden guardar relación con las Ciencias Biomédicas en general ${ }^{5}$.

\footnotetext{
La concreción de los posibles derechos aplicables a la genética humana, además de los que se aluden en el texto sobre el respeto a la dignidad de la persona e igualdad, ha sido propuesta por Kutukdjian G. Genética y Derechos Humanos. Revista de Derecho y Genoma Humano 1995; 2: 211, en estos términos: protección de los derechos de las personas vulnerables, derecho a no ser objeto de experimentos médicos o científicos sin el libre consentimiento, derecho a los mayores niveles posibles de salud física y mental, derecho a la protección contra la injerencia arbitraria en la intimidad personal o familiar, derecho a disfrutar de los beneficios del progreso científico y su aplicación, derecho a la libertad de la investigación científica. A todos ellos, que asume, añade el derecho a la vida, que es aplicable a todos los miembros de la familia humana, incluidos los no nacidos. Fleming JI. La ética y el Proyecto Genoma Humano sobre Diversidad. Revista Derecho y Genoma Humano 1996; 4: 182.
} 
La preocupación más intensa en los últimos decenios se ha dirigido a establecer todos los mecanismos jurídicos y políticos posibles para garantizar el respeto de esos derechos humanos y ha llevado a constitucionalizarlos, a convertirlos en preceptos del máximo rango normativo(7).

Podemos convenir en la plena vigencia de los derechos humanos, entendidos como un conjunto de facultades que, en cada momento histórico, concretan las exigencias de la dignidad, la libertad y la igualdad humanas, las cuales deben ser reconocidas positivamente por los ordenamientos jurídicos a nivel nacional e internacional $(7, p .48)$ y que, en cierto número de Estados, forman parte también de los derechos fundamentales ${ }^{6}$, que serían "aquellos derechos humanos garantizados por el ordenamiento jurídico positivo, en la mayor parte de los casos en su normativa constitucional, y que suelen gozar de una tutela reforzada"(7).

En los epígrafes que siguen podrá comprobarse cómo el Derecho relativo al genoma humano y -con menor intensidad- a las biotecnologías, si bien tiene su origen en un soft law (normas jurídicas no esencialmente obligatorias ni coercitivas, sino más bien exhortativas), sobre todo en el ámbito del Derecho Internacional, ha ido transitando de forma paulatina y constante hacia un Derecho caracterizado por normas de determinación, por su obligatoriedad, al estar ya respaldadas cada vez con mayor frecuencia por sanciones y otras consecuencias jurídicas.

\footnotetext{
La conexión propuesta de los derechos fundamentales con los Derechos Humanos y éstos -en parte- con el Derecho Natural, ha cuestionado el recurso a éste para la interpretación o complemento de los primeros, resolviéndose en la actualidad en sentido negativo por amplios sectores. Véase sobre el particular, Bleckmann A. Staatsrecht II. Die Grundrechte. Köln: Carl Heymanns Verlag; 1989: 57, quien señala que es distinto que la constitución proyecte un Derecho natural positivizado.
}

\subsection{El Derecho Internacional, fuente de expansión de los derechos humanos en el ámbito del genoma humano}

Ya en el Preámbulo de la Declaración Universal de Derechos Humanos, de 10 de diciembre de 1948, se proclaman los principios o valores que impregnan a todo el texto articulado: "la libertad, la justicia y la paz en el mundo tienen por base el reconocimiento de la dignidad intrínseca y de los derechos iguales e inalienables de todos los miembros de la familia humana".

En el campo específico de las ciencias biomédicas se ha venido desarrollando o identificando numerosos derechos humanos $(8-$ 10), en ocasiones como parte del contenido de algunos derechos fundamentales proclamados por la mayor parte de las Constituciones modernas (por ejemplo, el derecho a la vida, a la integridad física, a la libertad ideológica o de conciencia, a la intimidad y a la vida privada, etc.), pero también inspirados en la Declaración Universal, en los pactos internacionales (en particular, el Pacto Internacional sobre Derechos Civiles y Políticos de 1966) o en convenios regionales, como es, en el caso europeo, el Convenio sobre Derechos Humanos y libertades fundamentales de 1950, y en el americano, la Convención Americana sobre Derechos Humanos de 1969. Sin embargo, en la identificación de nuevos derechos humanos o de, al menos, las nuevas perspectivas que ofrecen en relación con los avances científicos, ha significado un paso cualitativo el Convenio del Consejo de Europa sobre Derechos Humanos y Biomedicina, de 4 de abril de 1997, que ya se ha incorporado al derecho interno de varios países -entre ellos al de España-, con fuerza vinculante y obligatoria para los poderes públicos respectivos. Y, aún sin ese efecto obligatorio, pero con una indiscutible fuerza moral de orientación para los Estados, lo es también la Declaración Universal de la UNESCO sobre el Genoma Humano y los Derechos Humanos, de 11 de noviembre de 1997. 


\subsection{La influencia del Derecho Internacional en el Derecho Interno respecto a la protección de los derechos humanos}

La cada vez más estrecha vinculación entre Derecho Internacional y Derecho Interno -o estatal- apuntada más arriba se ha revelado sobre todo en relación con los derechos humanos, y se ha señalado que en el futuro inmediato será cada vez más intensa en el ámbito específico de las ciencias biomédicas. Esta observación es de enorme importancia, dado que, por razones obvias, hasta fechas muy recientes apenas podíamos encontrar en los textos jurídicos internacionales o constitucionales internos referencias explícitas a los derechos humanos afectados por los recientes avances científicos, sin perjuicio de que esta situación está experimentando un cambio radical.

Afortunadamente, contamos con otros refuerzos integradores de los derechos, bienes o valores nuevos o renovados que van aflorando a partir de las aplicaciones de algunos resultados de las ciencias biomédicas:

$1^{\circ}$ Por un lado, la remisión expresa de algunas constituciones a la Declaración Universal de Derechos Humanos y a otros Convenios internacionales para la interpretación de los derechos fundamentales, en los que el respectivo Estado haya sido parte ${ }^{7}$. Como veremos más abajo, esta previsión es de la máxima importancia en relación con el Convenio Europeo sobre Derechos Humanos y Biomedicina y otros semejantes que pudieran aprobarse en el futuro.

$2^{\circ}$ Por otro lado, los principios generales forman parte de los ordenamientos jurídicos internos -pero también del Derecho Internacional-, con su doble función integradora

7 Así, las Constituciones de España (art. 10.2) y de Portugal (art. 16.2) (fuente en la jerarquía de normas) e informadora (interpretativa) del ordenamiento jurídico. De este modo, el Derecho no se identifica sólo y exclusivamente con la Ley, sino que acoge también una serie de principios que se orientan a criterios de justicia material, pero que, aparentemente, no han tenido acogida explícita en la Ley y configuran, junto a la costumbre y -en algunos sistemas jurídicos- la jurisprudencia, la totalidad del ordenamiento jurídico. Según el criterio extendido entre los internacionalistas, en los principios generales del derecho se integrarían las Declaraciones Internacionales que no constituyen normas jurídicas coercitivas en sentido estricto, como ocurre con la Declaración Universal sobre los Derechos Humanos y con la Declaración Universal sobre el Genoma Humano y los Derechos Humanos.

Como se ha podido comprobar, no pocos de estos principios a su vez se han ido configurando también en el Derecho Internacional y son de extraordinaria importancia para lograr enfoques adecuados en relación con las ciencias biomédicas; es decir, una interacción del Derecho Internacional y el Derecho Interno cada vez más frecuente y profunda.

\subsection{Los derechos constitucionales del ciudadano "bioético" como respuesta a la biocracia}

El Derecho Constitucional presenta una enorme potencialidad, tanto como receptor de los derechos humanos que de forma más específica se ven involucrados por las ciencias biomédicas, como de instrumento para resolver los conflictos que de éstas emergen, de lo que encontramos numerosos ejemplos en el constitucionalismo comparado moderno. Indudablemente, constituyen una novedad del constitucionalismo contemporáneo los incipientes ejemplos existentes sobre el reconocimiento de algunos derechos relacionados con el genoma humano y las 
biotecnologías. Por lo demás, este proceso, que en sus inicios ha sido lento, es lógico: si los derechos humanos relacionados con estas materias se han asentado en el Derecho Internacional, es razonable que algunos derechos fundamentales tengan cabida en el moderno Derecho Constitucional en la medida en que ofrecen nuevas perspectivas para la protección de los ciudadanos. En este sentido, no cabe duda de la influencia que está ejerciendo el Derecho Internacional -y con toda seguridad continuará haciéndolo en el futuro- sobre este Derecho Constitucional de la Bioética en ciernes.

Así, en la Constitución de la Confederación Helvética se comenzó introduciendo el siguiente texto (1992): “El material genético de una persona no podrá ser analizado, registrado o revelado sin su previo consentimiento, salvo cuando expresamente lo autorice o lo imponga la ley" (art. 24). Con posterioridad, este precepto ha sido reemplazado por algunos artículos sobre la protección de la salud, el trasplante, la ingeniería genética no humana y en el ámbito humano, en cuanto materias que se reservan como competencia legislativa de la Confederación, sin prejuzgar su naturaleza o no de derechos fundamentales. Respecto a la última mencionada, prescribe: "Medicina reproductiva e ingeniería genética en el ámbito humano. 1. Todo ser humano debe ser protegido contra los abusos de la medicina reproductiva y de la ingeniería genética. 2 . Corresponde a la Confederación legislar sobre el patrimonio germinal y genético humano. A tal respecto vigilará por asegurar la protección de la dignidad humana, de la personalidad y de la familia y respetará en particular los siguientes principios: a. se prohíbe cualquier forma de clonación y de intervención en el patrimonio genético de los gametos y de los embriones humanos; b. el patrimonio genético y germinal no humano no puede ser transferido al patrimonio germinal humano ni fusionado con éste; c. el recurso a los procedimientos de procreación asistida sólo será autorizado cuando no pueda ser excluida de otro modo la esterilidad o el peligro de transmisión de una enfermedad grave, y no para desarrollar en el niño ciertas características o para fines de investigación; la fecundación de óvulos humanos fuera del cuerpo de la mujer únicamente será permitida en las condiciones establecidas por la ley; únicamente podrán desarrollarse fuera del cuerpo de la mujer hasta el estadio de embrión el número de óvulos humanos que pueda ser implantado a la mujer de forma inmediata; d. la donación de embriones y cualquier forma de maternidad por sustitución están prohibidas; e. no se permite el comercio del material germinal humano ni de los productos del embrión; f. el patrimonio genético de una persona únicamente podrá ser analizado, registrado o revelado con el consentimiento de ella o en virtud de una ley; g. todas las personas tendrán acceso a los datos relativos a su ascendencia" (art. 119).

Por su parte, la Constitución portuguesa ha proclamado otro importante derecho fundamental, que se refiere a un ámbito diferente del anterior, y en este sentido se complementan (1997): "La ley garantizará la dignidad personal y la identidad genética del ser humano, en concreto en la creación, desarrollo y utilización de las tecnologías y en la experimentación genética" (art. 26.3).

Estos preceptos constitucionales constituyen las primeras referencias con este rango a la libre autonomía del individuo, al patrimonio genético y a un derecho a la identidad genética del ser humano como derechos del ciudadano bioético, y configuran el núcleo de un Derecho Constitucional de la biomedicina, que se irá desarrollando en los próximos años como barrera frente a las presiones de ciertos investigadores y empresas que no reconocen ningún freno al progreso de la ciencia y al beneficio económico (los biócratas). 


\subsection{La emergencia de algunos bienes o derechos relacionados con el genoma humano}

Especialmente en el ámbito internacional, asistimos a la remodelación de valores vinculados con el genoma humano, cuya protección jurídica podría configurarlos como derechos subjetivos o como bienes jurídicos. He aquí algunos de ellos que, con mayor o menor nitidez, aparecen en la Declaración Universal de la UNESCO sobre el Genoma Humano y los Derechos Humanos y en el Convenio del Consejo de Europa sobre Derechos Humanos y Biomedicina:

La necesidad de respetar al ser humano, tanto en cuanto persona como por su pertenencia a la especie humana. Nótese que se acentúa no sólo la perspectiva individualista (y social y de grupos humanos) tradicional de los derechos humanos, sino, sobre todo y como novedad, la adscripción del ser humano a su grupo biológico natural, la especie, que potencialmente puede verse afectada por los avances en el conocimiento genético y en la intervención sobre el genoma humano.

- La preocupación por la especie humana no descansa en una mera visión estática de la misma, en relación con unos eventuales titulares de derechos más o menos identificables, sin perjuicio de la dificultad que en ocasiones presenta esta tarea. En efecto, la comprobación cada vez más evidente de que algunas acciones humanas se proyectan hacia el futuro de forma irreversible, sobre todo las vinculadas con los desarrollos tecnológicos y científicos y, en nuestro caso, en particular con la Biología Molecular y la Medicina reproductiva, plantea un nuevo dilema ético-filosófico, de extraordinaria dificultad para su anclaje jurídico, pero no irresoluble: la responsabilidad de las actuales generaciones para con las futuras y, yendo más allá, los posibles derechos de las generaciones futuras: ¿tendrán derechos en el futuro - cuando existan- o tienen ya derechos ahora? ¿o es preferible buscar otras formas de protección de sus intereses desvinculadas de la tradicional adscripción de derechos subjetivos a un titular determinado? Lo cierto es que es ésta una perspectiva sobre la que se ha adquirido conciencia y que ya no puede arrinconarse(11) y, desde luego, puede ser también relevante para la valoración de diversas formas de intervención en el genoma humano, como la línea germinal y la clonación reproductiva. Al menos en el Derecho Internacional se apela ya a que los progresos en la Biología y en la Medicina deben ser aprovechados tanto en favor de las generaciones presentes como futuras.

- La proclamación de la vigencia, también en relación con los descubrimientos sobre el genoma humano y las posibles aplicaciones de los mismos, de los principios universales de igualdad y no discriminación, de los derechos a la libertad, integridad e intimidad. Esto, sin perjuicio del reconocimiento de otros valores, como son algunos de los que se mencionan a continuación.

- La protección de la identidad del ser humano, cuyo alcance, sin embargo, no se especifica por los instrumentos internacionales, puede referirse tanto a la identidad personal como a la biológica o genética. Sea cual fuere la extensión de su contenido, no cabe duda que, conceptualmente, abarca la idea del ser humano como ser único y distinto a los demás desde esas dos perspectivas. Se trata de otra de las consecuencias que se derivan de los avances en el conocimiento genético $\mathrm{y}$ en la intervención sobre el genoma humano.

- Consideración del genoma humano como patrimonio de la humanidad y por ello merecedor de protección específica. De este modo se reconduciría el enfoque hacia el patrimonio genético como bien de toda la humanidad, de la especie humana, del que 
sería depositaria ésta en su conjunto, incluidas las generaciones futuras, e implicaría su inapropiabilidad en cuanto tal, tanto de forma individual como colectiva, su intangibilidad e integridad (salvo por motivos terapéuticos) $\mathrm{y}$, en consecuencia, también la integridad de la especie humana ${ }^{8}$. Es decir, se trataría de atribuirle un significado espiritualizado, en la dirección en que, para determinados casos, se ha ido puliendo el concepto de "patrimonio de la humanidad" en el Derecho Internacional.

A pesar de la relevancia que puede tener tal concepto en el futuro, si se logra un adecuado desarrollo y aplicación del mismo, es cierto que esta idea fue asumida demasiado rápidamente antes de haber profundizado previamente y de forma suficiente sobre su verdadero significado y alcance, sobre su contenido $\mathrm{y}$, finalmente, sobre la adecuación misma e irrefutabilidad de la afirmación ${ }^{9}$, pues tal discurso abocaría en su maximalización a la sacralización del patrimonio genético como último reducto, de tal forma que no admitiría excepciones de ningún tipo a su intangibilidad, lo que puede ser excesivo.

\footnotetext{
Sus antecedentes pueden encontrarse en la Recomendación 934 (1982), sobre Ingeniería Genética, del Consejo de Europa, recomendación 7, b: "Recomienda al Comité de Ministros... prever el reconocimiento expreso, en la Convención Europea de Derechos del Hombre, del derecho a un patrimonio genético que no haya sufrido ninguna manipulación, salvo en aplicación de ciertos principios reconocidos como plenamente compatibles con el respeto de los derechos humanos (por ejemplo, en el campo de las aplicaciones terapéuticas)"; y la Recomendación 1046 (1986), relativa a la utilización de embriones y fetos humanos con fines diagnósticos, terapéuticos, científicos, industriales y comerciales, del mismo organismo (principo 1, que recoge el texto transcrito de la Recomendación 934/1982).

9 También crítico, pues considera que "se cae de nuevo en la falacia naturalista", Gracia Guillén D. Libertad de investigación y biotecnología. En Gafo J, ed. Ética y Biotecnología. Madrid: F. Humanismo y Democracia Universidad Pontificia de Comillas; 1994: 23. Asimismo, Knoppers BM. Human Dignity and Genetic Heritage. Ottawa: Law Reform Commission of Canada; 1991: 74.
}

Sin embargo, se ha preferido finalmente plasmar la extraña afirmación de que, "en sentido simbólico, el genoma humano es el patrimonio de la humanidad", lo que habría de tener como efecto un desdibujamiento de su relevancia jurídico-conceptual y hasta un vaciamiento de su contenido. Pero de ello nos ocuparemos en otro lugar.

- El reconocimiento de la diversidad biológica de todos los seres vivos, por consiguiente, incluyendo la especie humana, como un bien merecedor de protección.

- La selección o modificación de las características genéticas o de los rasgos fenotípicos sólo es lícita si va encaminada a la prevención de enfermedades hereditarias graves, sin perjuicio de otras limitaciones más discutibles, sobre todo si se piensa en un futuro todavía no determinado (p. ej., no modificar el genoma de la descendencia).

- El respeto de la autonomía y de la integridad física y mental (incluida la integridad genética) del ser humano en el proceso de una experimentación, siendo prevalente el interés y bienestar de éste frente al interés exclusivo de la sociedad o de la ciencia.

- El derecho a la participación en los beneficios que proporcionan los avances científicos y tecnológicos en cuanto tales, sin limitaciones basadas en diferencias culturales, geográficas o de recursos, lo que exige, entre otras medidas, la libre circulación del conocimiento científico.

Las referencias al derecho a la vida, base y soporte de todos los demás derechos, no suelen ser explícitas en este contexto, bien que este derecho planea de forma casi constante en estas materias, como sucede con los dilemas que suscita el comienzo de la vida humana y sus formas previas a la gestación en relación con las posibilidades de acceso que han abierto las técnicas de reproducción 
asistida en conjunción con otras biotecnologías. Esto contrasta con la lógica enfatización que ha merecido este derecho en la Declaración Universal de Derechos Humanos y en otros convenios internacionales sobre los derechos humanos ${ }^{10}$, pero ello no es óbice para que sea ejercitable con toda su fuerza cuando resulte necesario.

\subsection{La dignidad humana en las aplicaciones derivadas de las Ciencias Biomédicas, en particular en relación con el genoma humano}

A la dignidad humana se recurre con asiduidad cuando se debaten los aspectos éticos y jurídicos que afectan a las Ciencias Biomédicas. A este respecto, así lo proclama expresamente la Declaración Universal de la UNESCO sobre el Genoma Humano y los Derechos Humanos en varios pasajes de su articulado: así, p. ej., "cada individuo tiene derecho al respeto de su dignidad y derechos, cualesquiera que sean sus características genéticas" (art. 2, b); asimismo, al considerar la clonación con fines de reproducción humana como contraria a la dignidad humana (art. 11); y al rechazar por el mismo motivo la terapia génica en la línea germinal (art. 24). Por su parte, el Protocolo Adicional al Convenio del Consejo de Europa sobre Derechos Humanos y Biomedicina sobre la prohibición de clonar seres humanos, de 12 de enero de 1998, en su Exposición de Motivos vincula expresamente tal posible práctica con la dignidad humana, cuando recuerda que es fin del Convenio proteger la dignidad e identidad de todos los seres humanos (art. $1^{\circ}$, párr. $1^{\circ}$ de este último).

Son cada vez más los instrumentos jurídicos internacionales que proclaman la dignidad de

\footnotetext{
${ }^{10} \mathrm{DUDH}$, art. $3^{\mathrm{o}}$; Pacto Internacional de Derechos Civiles y Políticos, art. $6^{\circ}$; Convenio Europeo sobre Derechos Humanos y libertades fundamentales, art. $2^{\circ}$; Convención Americana sobre Derechos Humanos, art. $4^{\circ}$; Carta Africana sobre los Derechos Humanos y de los pueblos, art. $4^{\circ}$.
}

la persona como un predicado del ser humano que debe permanecer intangible $(10, p$. 44) y algunos textos constitucionales también la mencionan expresamente. Ejemplos relevantes de estos últimos, en cuanto reflejan criterios diferentes, son la Ley Fundamental alemana de $1949\left(\right.$ art. $1^{\circ}$ ) y la Constitución de la Confederación Helvética $\left(\right.$ art. $7^{\circ}$ ), que la proclaman como derecho fundamental -en el sentido estricto señalado más arriba-, y la Constitución española (art. 10.1), donde, sin embargo, no figura con este rango, lo que ha motivado que el Tribunal Constitucional español no haya otorgado el amparo en aquellas partes de- los recursos de esta naturaleza que han alegado un atentado a la dignidad humana. ¿Significa esto que su inclusión en la Constitución española es meramente retórica, sin ningún contenido jurídico? En efecto, no es un derecho fundamental, pero es, en cierto sentido, mucho más que eso. Algo semejante puede apuntarse de la Constitución brasileña, donde la dignidad de la persona humana es uno de los fundamentos del Estado Democrático de Derecho (art. 1.III).

La dignidad de la persona se configura como el principio informador y la raíz de los derechos básicos del hombre reconocidos como fundamentales por la Constitución española, sobre los que se proyecta y constituye su filtro interpretativo, integrador y valorativo de aquéllos para los poderes públicos(10, p. 111). Por ello suele reconocerse que la mayor parte de los derechos fundamentales presenta un contenido nucleico referido a la dignidad de la persona ${ }^{11}$, lo que explica la función informadora e interpretativa que se le atribuye sobre los mismos. Quizá su manifestación más patente en el texto constitucional la encontremos en la prohibición de tratos inhumanos o degradantes (art. 15 de la Constitución española), junto al

\footnotetext{
${ }^{11}$ Así, expresamente, Zippelius R. Kommentar zum Bonner Grundgesetz. $3^{\mathrm{a}}$ ed. 1989: anot. marg. 13 al art. $1^{\circ}$.
} 
derecho a la integridad física y moral, además de los de libertad, igualdad y no discriminación y otros, recogidos específicamente en la Constitución española: "La Constitución... ha elevado también a valor jurídico fundamental la dignidad de la persona, que, sin perjuicio de los derechos que le son inherentes, se halla íntimamente vinculada con el libre desarrollo de la personalidad (art. 10) y los derechos a la integridad física y moral (art. 15), a la libertad de ideas y creencias (art. 16), al honor, a la intimidad personal y familiar y a la propia imagen (art. 18. 1)"12 . Por tanto, la dignidad humana puede ser lesionada a través de o en conexión con la agresión de alguno de los concretos derechos fundamentales, sin que, no obstante, toda lesión de los mismos implique necesariamente también la de la dignidad, según ha matizado el Tribunal Constitucional español: el que la dignidad de la persona y los derechos inviolables que le son inherentes sean fundamento del orden político y la paz social "no significa ni que todo derecho le sea inherente -y por ello inviolable-, ni que los que se califican de derechos fundamentales sean in toto condiciones imprescindibles para su efectiva incolumidad, de modo que de cualquier restricción que a su ejercicio se imponga devenga un estado de indignidad"13. En consecuencia, por sus propias características, la dignidad humana no puede situarse en los términos habituales de ponderación como un interés, más allí donde surge el enfrentamiento o colisión entre derechos fundamentales o bienes jurídicos constitucionales, sino que es preciso constatar si en la situación concreta la dignidad humana se ha visto o no en cuanto tal afectada, lo que la califica como principio material de justicia(12).

\footnotetext{
${ }_{12}$ Sentencia del Tribunal Constitucional 53/1985, de 11 de abril. En términos semejantes, ya la sentencia 107/1984, de 23 de noviembre.

13 Sentencia 127/1990, de 27 de junio.
}

Por otro lado, al constituir la dignidad humana el "fundamento del orden político y de la paz social" obliga jurídicamente a todos los poderes públicos a su respeto y protección, y constituye "un mínimum invulnerable que todo estatuto jurídico debe asegurar" teniendo presente que "en cuanto valor espiritual y moral inherente a la persona, la dignidad humana permanece inalterada cualquiera que sea la situación en que la persona se encuentre"14 . Es decir, se trata de una norma constitucional obligatoria.

Finalmente, si bien es algo distinto de un derecho fundamental, la idoneidad proyectiva e informadora de la dignidad humana sí que permitiría obtener a su través la identificación de nuevos aspectos no directa o unilateralmente deducibles de los concretos derechos fundamentales recogidos en la Constitución española por sí solos, pero sí intrínsecos o emanaciones de ella y, en este sentido, exigibles como derechos subjetivos en cuanto que, de acuerdo con este procedimiento interpretativo, tengan cabida en el correspondiente derecho fundamental. Esta concepción dinámica, integradora, abierta y expansiva se concilia, además, con la Constitución española, al obligar a interpretar las normas relativas a los derechos fundamentales y a las libertades públicas que consagra de conformidad con la Declaración Universal de Derechos Humanos y los Tratados y Acuerdos internacionales sobre las mismas materias en los que España sea parte (art. 10.2). A este respecto, es fundamental recordar una vez más el Convenio sobre Derechos Humanos y Biomedicina, puesto que su art. $1^{\circ}$ declara, ahora de forma general, que "las partes en este Convenio protegerán la dignidad e identidad de todo ser humano..."

Aclarados los criterios anteriores, debe mencionarse también que en no pocas ocasiones

${ }^{14}$ Sentencia 120/1990, cit. 
se recurre a la dignidad humana como un argumento definitivo, sin profundizar más en el contenido de los intereses o bienes en conflicto, en cómo puede verse afectada en concreto la dignidad humana y cuál es su consecuencia jurídica. Se convierte entonces en un argumento de autoridad, pero vacío y opuesto al diálogo. Como ha denunciado en esta dirección Arthur Kaufmann, la dignidad humana tiene valor en el discurso internacional cuando se quiere designar con ella un consenso existente, pero no es un argumento idóneo para construir un consenso inexistente, pues es "demasiado abstracta y general, además, de contenido cambiante"(13). Sólo si el mandato de respeto de la dignidad humana, concluye, se concreta y se positiviza es posible argumentar materialmente con él.

\section{Referencias}

1. Romeo Casabona CM, ed. La eugenesia hoy. Bilbao - Granada: Editorial Comares; 1999.

2. Duster T. Human Genetics, Evolutionary Theory, and Social Stratification. En: Frankel MS, Teich AH, eds. The Genetic Frontier. Ethics, Law and Policy. Washington DC: American Association for the Advancement of Science; 1994: 131.

3. Soutullo D. La eugenesia. De Galton hasta hoy. Madrid: Editorial Talasa; 1997.

4. Martínez de Pisón J. Derechos Humanos: historia, fundamento y realidad. Zaragoza: Egido Editores: 1997: 171.

5. Gracia D. Fundamentos de Bioética. Madrid: EUDEMA: 1989: 579.

6. Gros Espiell H. Constitución y Bioética. En Romeo Casabona CM, coord. Derecho Biomédico y Bioética. Granada: Editorial Comares y Ministerio de Sanidad y Consumo; 1998: 137.

7. Pérez Luño AE. Los derechos fundamentales. Madrid: Tecnos; 1988: 37.

8. Gros Espiell H. Genética y Derechos Humanos. Anuario Hispano-Luso Americano de Derecho Internacional 1995; Vol. XII.

9. Rodotà S. Le droit face aux dilèmmes moraux de la vie et de la mort. En: XXth Colloquy on European Law. Glasgow 1990; Council of Europe, Strasbourg 1992: 16.

10. Romeo Casabona CM. La Bioética y el Derecho ante los límites de la vida humana. Madrid: Editorial Centro de Estudios Ramón Areces; 1994: 65.

11. Pontara G. Ética y generaciones futuras. Barcelona: Ariel; 1996: 104.

12. Cerezo Mir J. Curso de Derecho Penal Español. Madrid: Tecnos; 1996: 18.

13. Kaufmann A. Filosofia del Derecho. Santa Fe de Bogotá: Publicaciones Universidad Externado de Colombia; 1999: 552. 